Research Article

\title{
Discussion on the Design and Performance of the Whole Packaging Box of Environmentally Friendly Packaging Materials
}

\author{
Mengwei Xie $\mathbb{i}^{1,2}$ \\ ${ }^{1}$ Design and Manufacturing Collaborative Innovation Center, China Academy of Art, Hangzhou 310012, Zhejiang, China \\ ${ }^{2}$ Art Academy, Yunnan Minzu University, Kunming 650504, Yunnan, China
}

Correspondence should be addressed to Mengwei Xie; 20191083@caa.edu.cn

Received 21 August 2021; Revised 25 October 2021; Accepted 5 November 2021; Published 24 November 2021

Academic Editor: Wei Liu

Copyright $\left({ }_{0} 2021\right.$ Mengwei Xie. This is an open access article distributed under the Creative Commons Attribution License, which permits unrestricted use, distribution, and reproduction in any medium, provided the original work is properly cited.

\begin{abstract}
More and more designers and companies in the packaging industry begin to pay attention to research on environmentally friendly packaging design. From studying the additional functions of packaging to starting to study the environmentally friendly materials of packaging, as well as the "zero-pollution" packaging advocated today, the traditional form and mode of packaging has changed. This article aims to study the design of the overall packaging box of environmentally friendly packaging materials and discuss its performance. In this paper, the platform construction method and the modulus definition classification method are used to calculate the positive axis stiffness of the single-layer board. The effect of coating process on the wear resistance of paper-based materials was studied, the wear resistance of box board base paper and coated box board under different temperatures and different humidity conditions was compared, and the optimal design variable value range was set. The experimental results show that after the first level of optimization, the overall mass of the structure is reduced from the initial $39.42 \mathrm{~kg}$ to $31.18 \mathrm{~kg}$ and the optimization efficiency is $20.90 \%$; the maximum relative deformation of the flap structure has increased from $0.143 \mathrm{~mm}$ to $0.198 \mathrm{~mm}$, despite having the maximum tension. The opening displacement has increased, but it still meets the sealing deformation requirements. The design and performance discussion of the overall packaging box of environmentally friendly packaging materials have been completed relatively well.
\end{abstract}

\section{Introduction}

With the development of social science, designers are no longer restricted by materials, technology, and money. People work hard to explore and explore all aspects of design, but designers often fall into misunderstandings and start to make novel designs, for example, design new materials with various functions and physical effects, such as new ceramic materials, new metal materials, optical fiber materials, and packaging materials. More product packaging on the market is addicted to excessive product stimulus consumption, and more designs begin to enjoy sensory stimulation. At present, the basic task of the designer is to create a more logical way of use for the public to care for nature and human development. In recent years, packaging has become a way to select and process products to enhance the brand. In this process, the final recycling becomes an important goal. Packaging design can play an important role in improving resource recovery and solving high energy consumption production. The concept of green packaging has been adopted by many designers at home and abroad, but few packaging designs can be made using this concept. At present, various designers have done a lot of case studies and studies on structures and materials and have explored various aspects from recycling to reducing packaging costs, so as to create a more realistic, healthier, and more meaningful future for mankind. The "zero-pollution" packaging design was born and developed.

With the rapid development of high and new technology, the requirements for the performance of new materials have also become higher and higher, which puts forward higher requirements for the development of materials science itself. New materials refer to newly developed or developing structural materials with excellent properties and 
functional materials with special properties. To design a new type of material that meets the expected requirements and manufacture it through advanced processes and technologies, it is necessary to have a deep understanding of the relationship between the material's microstructure and macroscopic properties and theoretically assume a material system with a specific structure and function. The microstructure of a material refers to the structure of the atoms, ions, and molecules that make up a substance, and there is a great relationship between the macroscopic properties. Changes in the microstructure will lead to changes in the macroscopic properties of the material. For example, C60 and diamonds: the same material is composed of carbon atoms but constitutes two different substances. In the context of the rapid development of computer-aided technology, computer simulation is a way of materials science. The method is to simulate the composition, microstructure, process, and performance of the material based on computer simulation; computer simulation has become an important technical means to solve practical problems in materials science. Combined with a powerful computing system and a variety of specific algorithm simulation techniques, researchers have been able to achieve unprecedented detailed simulation and extremely precise research on the internal conditions of materials. The advantage of using computer simulation to conduct in-depth research on materials is that it cannot only simulate various experimental processes and understand the relationship between the internal microstructure of the material and the macroscopic material properties, but also can predict its macroscopic properties before the actual preparation of new materials. This provides theoretical guidance for the design of excellent new materials. When calculating materials, first choose an appropriate method based on the objects, conditions, requirements, and other factors to be calculated. To make a good choice, you must understand the classification of material calculation methods. The performance of a material depends to a large extent on the microstructure of the material, and the use of the material is different, and the microstructure scale that determines its performance will vary greatly. This kind of simulation experiment in material science research is more economical, efficient, and flexible than the experiment itself and can play its unique role in occasions where the experiment itself is difficult to achieve or cannot be carried out, especially in understanding the microstructure and its unique simulation experiment method. It is irreplaceable.

In recent years, many domestic and foreign scholars have conducted in-depth discussions and researches on this issue. Neves et al. studied the relationship between the compression deformation ability of the corrugated sandwich panel and its plastic vibration absorption ability and established a mathematical model of material friction and wear. But his research did not discuss the friction and wear mechanism of materials [1]. Wang studied the performance of corrugated cartons under vertical dynamic loads; dynamic load refers to the load on the body under the influence of vibration, environment, and other factors during the movement. He simplified the loaded cartons into a spring system and proposed that the main reason for the failure of cartons during transportation is the dynamic load caused by vibration. But his research did not get the dynamic behavior of paper packaging and the corresponding formula [2]. Vahid and Iman have verified through a large number of experiments that when the input frequency of the corrugated box vibration is close or equal to the resonance frequency of the carton system, the dynamic load of the corrugated box will increase exponentially, which can be said to be a step closer to the foundation of the predecessors. But their research did not propose the corresponding algorithm and formula [3]. Nurul et al. successively proposed and developed the Holm-Archard model. The Holm-Archard model is an important tool for studying mold wear, steady-state deformation, adhesive wear models, and numerical analysis of wheel wear. This formula was originally used to analyze the mechanism of material adhesion wear, but later it was proved that the formula has similar expressions for other wear methods [4]. Wang et al. established an abrasive wear model based on the plastic deformation of the material. The strain range of the model is generated by a tapered wear surface. They also proposed that there is a critical strain value. If the critical value is exceeded, wear debris will be generated [5]. The research of Dissanayake et al. found that the ultrasonic wave is applied in the moving plane to make it vibrate. When the vibration frequency is given by the ultrasonic wave reaching $20 \mathrm{MHz}$ or more, the friction decreases. However, his research did not carry out SEM observation on the worn surface of the material and the morphology of the abrasive [6]. The photosensitive coating material is a relatively important material on the packaging surface. It causes the color change of the photochromic material after being exposed to sunlight/ ultraviolet rays; when it loses sunlight/ultraviolet rays, it will return to its original color. Puscaselu uses the paper strip contact drum method to measure the friction coefficient between paper-based materials. In his research, the photoelectric counting technology is used to measure the friction coefficient of the photosensitive coating surface of the blueprint material. But his research did not study the improvement of the performance and coating of paper-based materials from the aspect of microscopic materials [7].

The innovations of this paper are as follows. (1) The concept of zero-pollution packaging design is proposed, which combines the production process and application of plastic profiles with the concept of green environmental protection to meet the development needs of the new era. (2) According to the assumption of invariance of the straight normal, the strain at the middle distance $z$ in the laminate is defined, and the Cauchy equation is used, which greatly improves the data accuracy of the algorithm. (3) In the discussion section, the relationship between materials and packaging design is proposed, and aesthetic ideas such as the perception of the visual beauty of materials in packaging design are perceived, and the humanities content and the science and engineering thinking content are combined, making the research introduction very comprehensive. 


\section{Design and Performance of the Overall Packaging Box of Environmentally Friendly Packaging Materials}

2.1. Concept of "Zero-Pollution" Packaging Design. Zero pollution can also be understood as "zero-waste" [8]. It originally came from the concept of zero waste proposed in the field of waste recycling [9]. This concept can be applied to packaging design and can also be applied to modern green environmental protection design concepts. This is actually one of the designs they support. This method supports the redesign of packaging material resources [10], reducing or not generating packaging waste. On this basis [11], the concept of zero-pollution packaging design came into being, considering the final problem from the source of the design [12]. The point is such that when the packaging function of the product packaging is completed, the packaging can also become a part of the product, achieving the purpose of not generating any garbage in the packaging and solving the problem of packaging pollution [13] and so making continuous use of pollution-free packaging [14].

The zero-pollution packaging design covers the whole process of packaging basic products, from materials, structure, and decoration to the final packaging waste, with functional optimization as the main goal [15]. Zero-pollution packaging design is currently a method and development direction for people to solve environmental pollution problems in the field of packaging design. Its main purpose is to help society solve the pollution problem [16]; it can balance the contradiction between human development and the natural environment and find the best way [17]. Zeropollution packaging has been tried abroad. For example, as edible wrapping paper, Japan has developed a wrapping paper made of chitosan polysaccharides extracted from shell materials. The Coca-Cola Company designed a self-melting ice bottle. The label on the bottle can protect consumers' hands and can be used as a wristband after use. The packaging materials are edible and easy to evaporate, having modern high-tech materials. They are solved through the daily human behavior after packaging and use, so as to solve the problems and contradictions in life and try to provide consumers with safety and convenience, bringing greater benefits [18]. The so-called zero-pollution package puts safety first. In addition to the basic functions of zero-pollution packaging to ensure packaging protection and safe transportation, all insignificant decorative elements must also be carefully removed [19]. Zero-pollution packaging not only has no waste pollution after packaging but also minimizes the structure and decorative elements of packaging materials, reduces unnecessary external transformations, reduces costs, and saves resources [20].

"Zero-pollution" packaging design is made to disappear the moment the product is used, besides the development direction of the so-called "zero-waste" packaging, so that the packaging itself can become a product. After the packaging function is used, according to the various environmental recycling characteristics of packaging materials, we will try to reduce the environmental impact of waste packaging pollution to "zero". The starting point of zero-pollution packaging design is not only to give people more beautiful and practical packaging, but, more importantly, it can arouse people's positive emotions and reduce the difficulties they face [21]. In the past, packaging designers only focused on the role of graphic agents in packaging design, but, now, designers realize that they can take the design as a whole and establish emotional connections with consumers and the market [22]. On the surface, the function of packaging is protecting the product, but this is also the easiest standard to meet. Faced with the current lack of environmental and social resources, it is the responsibility of packaging designers to awaken the environmental awareness of consumers and the entire society [23]. Zero-pollution packaging design can capture the emotional bond between consumers and society and remind designers to explore what improvements and research are being made on current product packaging design [24]. The overall plan of the plastic profile packaging line is shown in Figure 1.

\subsection{Production Process and Application of Plastic Profile.} Extrusion molding is a method in which materials are continuously passed through a die in a flowing state by heating and pressurizing in an extruder, also known as "extrusion". Compared with other molding methods, it has the advantages of high efficiency and low unit cost. The extrusion method is mainly used for the molding of thermoplastics and can also be used for some thermosetting plastics. The extruded products all have continuous profiles, such as tubes, rods, wires, plates, films, wire, and cable coatings. In addition, it can also be used for mixing, plasticizing, granulating, coloring, blending, etc. of plastics. Plastic profiles are plastic products with irregular crosssections made by extrusion molding methods. They have a wide range of applications [25], especially plastic doors and windows. Plastic profiles are generally extruded through a plastic extruder, and the production process is shown in Figure 2.

The plastic film keyboard made of the finally obtained plastic profile section is shown in Figure 3.

2.3. Material Selection of Composite Packaging Boxes. The composite packaging box should be selected according to the specific performance requirements of the packaging box, and a composite material that combines a suitable reinforcement material and a matrix material should be selected. The properties of composite materials composed of different raw materials are also different, so the correct choice of materials is an important basis for designing composite packaging boxes.

At present, most of the reinforcing materials used in foreign composite packaging boxes are glass fiber, some of which are carbon fiber, and the matrix material is mostly epoxy resin or unsaturated polyurethane resin. Glass fiber is a kind of inorganic nonmetallic materials with excellent performance. There are many kinds of them. The advantages are good insulation, strong heat resistance, good corrosion 


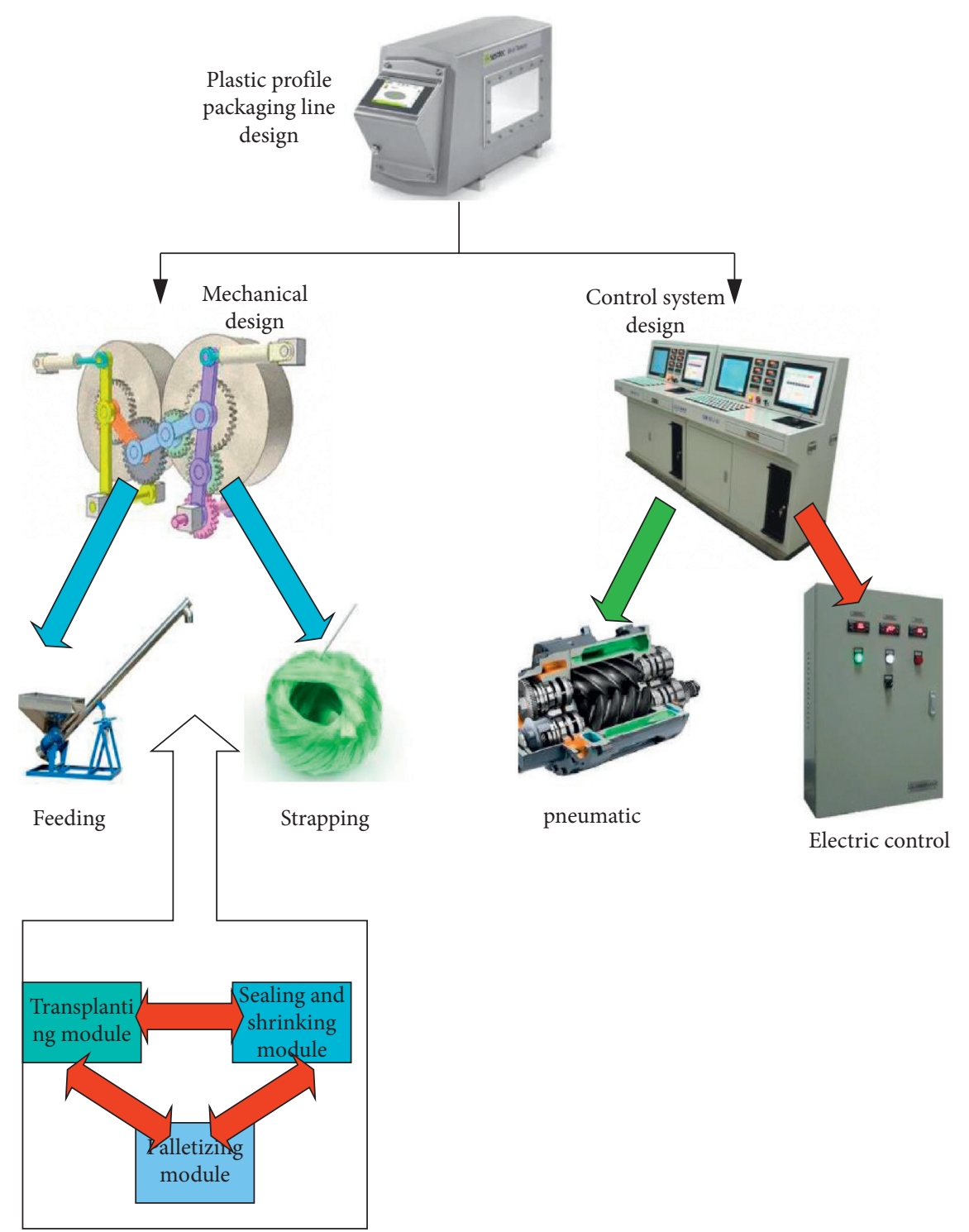

FIgURE 1: Plastic profile line diagram of the overall package.

resistance, and high mechanical strength. Carbon fiber is a special fiber composed of carbon elements. It has the characteristics of high temperature resistance, friction resistance, electrical conductivity, thermal conductivity, and corrosion resistance. Glass fiber was chosen because of its low price and good quality. Carbon fiber was chosen because it has better material properties than glass fiber and is suitable for more important occasions. Epoxy resin is chosen mainly because of its wide variety, easy hardening, strong adhesion, and low shrinkage. The cured epoxy resin has excellent mechanical and electrical properties and stable chemical properties. Since there are many types of glass fibers and epoxy resins, there are a large number of different combinations. In this paper, alkali-free glass fiber/epoxy resin composite material is selected as the raw material for the structural design of the packaging box. The following are the parameters related to the mechanical properties of materials, listing the performance parameters of such composite materials. In the design process of FRP packaging boxes, the reasonable choice of raw materials determines whether the casting process is feasible; on the contrary, the casting process also limits the materials. Therefore, in the initial stage of designing FRP packaging boxes, it is necessary to consider choosing a suitable casting process [26].

When designing the structure of the composite material, the suitability of the respective casting process of the composite material should be fully considered. The casting process of composite materials mainly includes manual casting, RTM casting, vacuum casting, die casting, winding casting, and autoclave casting. The performance of the composite product is greatly affected by the casting process, and the appropriate casting process should be selected according to the shape of the composite component and the performance of the raw material [27]. The shape of the glass fiber reinforced plastic packaging box is a thin-wall reinforced closed structure, and manual pouring or vacuum pouring process can be selected. In the case of using the same raw materials, the strength, stiffness, and other physical 


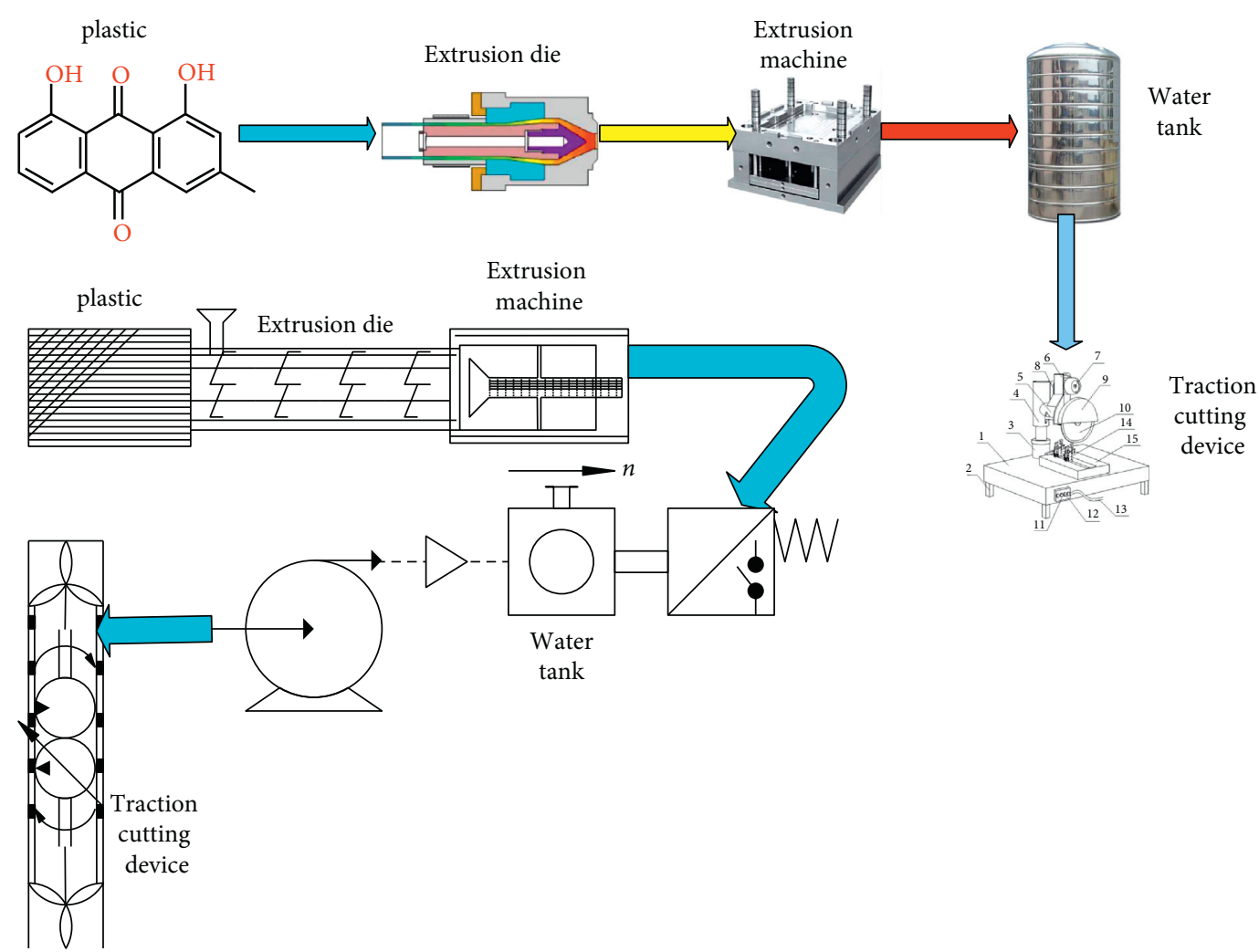

Figure 2: Plastic profile extrusion line.
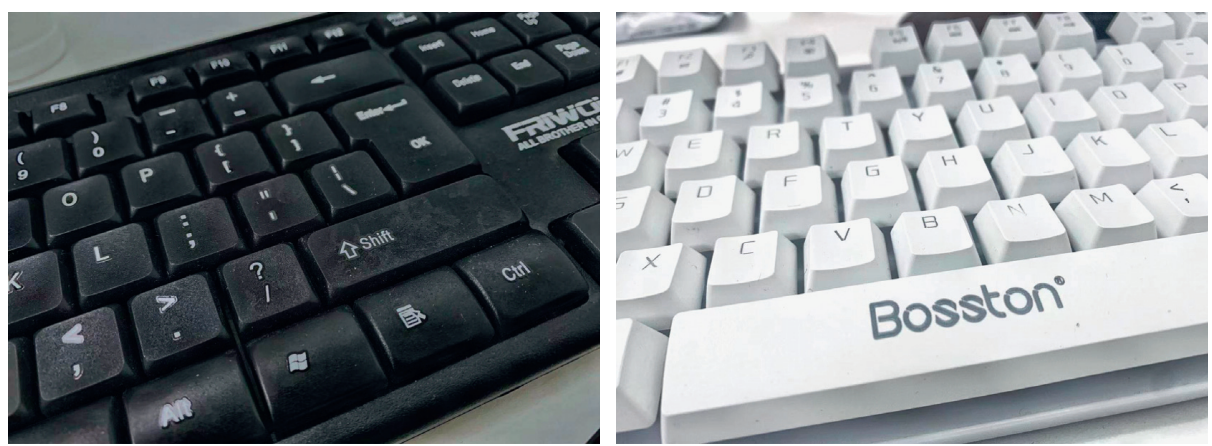

Figure 3: Plastic special-shaped membrane keyboard.

properties of the parts using the vacuum injection molding process can be increased by $30 \%$ to $50 \%$ or more than the parts using the vacuum injection molding process. Therefore, the vacuum injection molding process is preferred [28].

2.4. Positive Axis Stiffness of the Single-Layer Board. The positive axis stiffness of a single-layer board is the stiffness performance of the single-layer composite material on the positive axis. The positive axis stiffness has three forms of engineering elastic constant, modulus component, and compliance component, and these three forms can be converted mutually. The modulus component is the coefficient of the stress-strain relationship, usually used to find the stress from the strain, and is a set of basic constants for calculating the stiffness of the laminate. According to the stress-strain matrix relationship of the single-layer board, the modulus component is defined as

$$
\left[\begin{array}{c}
\sigma_{1} \\
\sigma_{2} \\
\sigma_{3}
\end{array}\right]=\left[\begin{array}{ccc}
Q_{11} & Q_{12} & 0 \\
Q_{12} & Q_{22} & 0 \\
0 & 0 & Q_{66}
\end{array}\right]\left[\begin{array}{c}
\varepsilon_{1} \\
\varepsilon_{2} \\
\gamma_{12}
\end{array}\right] .
$$

It is stipulated that the angle $\theta$ rotating from the off-axis $x$ to the positive axis 1 is positive when turning counterclockwise and negative when turning clockwise. If $m=\cos \theta, n=\sin \theta$, then 


$$
\begin{aligned}
{\left[\begin{array}{c}
\varepsilon_{1} \\
\varepsilon_{2} \\
\gamma_{13}
\end{array}\right] } & =\left[\begin{array}{ccc}
m^{2} & n^{2} & m n \\
n^{2} & m^{2} & -m n \\
-2 m n & 2 m n & m^{2}-n^{2}
\end{array}\right]\left[\begin{array}{c}
\varepsilon_{x} \\
\varepsilon_{y} \\
\gamma_{x y}
\end{array}\right] . \\
{\left[\varepsilon_{1}\right] } & =\left[T_{\varepsilon}\right]\left[\varepsilon_{x}\right] .
\end{aligned}
$$

From (1) to (3),

$$
\begin{aligned}
\left\{\sigma_{x}\right\} & =\left[T_{\sigma}\right]^{-1}[Q]\left[T_{\varepsilon}\right]\left\{\varepsilon_{K}\right\} \\
& =|\bar{Q}|\left\{\varepsilon_{x}\right\} . \\
{\left[\begin{array}{c}
\sigma_{x} \\
\sigma_{y} \\
\tau x y
\end{array}\right] } & =\left[\begin{array}{lll}
\bar{Q}_{11} & \bar{Q}_{12} & \bar{Q}_{16} \\
\bar{Q}_{12} & \bar{Q}_{22} & \bar{Q}_{26} \\
\bar{Q}_{16} & \bar{Q}_{26} & \bar{Q}_{66}
\end{array}\right]\left[\begin{array}{c}
\sigma_{1} \\
\sigma_{2} \\
\tau_{12}
\end{array}\right] .
\end{aligned}
$$

According to the assumption of invariance of the straight normal, the strain defining the distance to the midplane $z$ in the laminate can be expressed as

$$
\begin{aligned}
\varepsilon_{z} & =\frac{\partial w(x, y, z)}{\partial z}=0, \\
Y_{z x} & =\frac{\partial u(x, y, z)}{\partial z}+\frac{\partial w(x, y, z)}{\partial x}=0, \\
Y_{y z} & =\frac{\partial v(x, y, z)}{\partial z}+\frac{\partial w(x, y, z)}{\partial y}=0 .
\end{aligned}
$$

Integrating $z$, respectively, we can get

$$
\begin{aligned}
& w(x, y, z)=w(x, y) \\
& u(x, y, z)=u_{0}(x, y)-z \frac{\partial w(x, y)}{\partial x} \\
& v(x, y, z)=v_{0}(x, y)-z \frac{\partial w(x, y)}{\partial y}
\end{aligned}
$$

Substituting (8) into the Cauchy equation, we can get

$$
\begin{aligned}
\varepsilon_{x} & =\frac{\partial u_{0}}{\partial x}-z \frac{\partial^{2} w}{\partial x^{2}}, \\
\varepsilon_{y} & =\frac{\partial v_{0}}{\partial y}-z \frac{\partial^{2} w}{\partial y^{2}}, \\
\gamma_{x y} & =\left(\frac{\partial u_{0}}{\partial y}+\frac{\partial v_{0}}{\partial x}\right)-2 z \frac{\partial^{2} w}{\partial x \partial y} .
\end{aligned}
$$

It can be expressed in matrix form as

$$
\left[\begin{array}{c}
\varepsilon_{x} \\
\varepsilon_{y} \\
\gamma_{x y}
\end{array}\right]=\left[\begin{array}{c}
\varepsilon_{x}^{0} \\
\varepsilon_{y}^{0} \\
\gamma_{x y}^{0}
\end{array}\right]+z\left[\begin{array}{c}
\chi_{x} \\
\chi_{y} \\
\chi_{x y}
\end{array}\right]
$$

Among them,

$$
\{\chi\}=\left[\begin{array}{c}
\chi_{x} \\
\chi_{y} \\
\chi_{x y}
\end{array}\right]=-\left[\begin{array}{c}
\frac{\partial^{2} w}{\partial x^{2}} \\
\frac{\partial^{2} w}{\partial y^{2}} \\
2 \frac{\partial^{2} w}{\partial x \partial y}
\end{array}\right] .
$$

Here, $\varepsilon_{x}^{0}, \varepsilon_{x}^{0}$, and $\gamma_{x y}^{0}$ are the midplane strains of the laminate, and substituting $\{\varepsilon\}$ into $\{\sigma\}=|Q|\{\varepsilon\}$, we get

$$
\left[\begin{array}{c}
\sigma_{x} \\
\sigma_{y} \\
\tau_{x y}
\end{array}\right]_{k}=\left[\begin{array}{lll}
\bar{Q}_{11} & \bar{Q}_{12} & \bar{Q}_{16} \\
\bar{Q}_{12} & \bar{Q}_{22} & \bar{Q}_{26} \\
\bar{Q}_{16} & \bar{Q}_{26} & \bar{Q}_{66}
\end{array}\right]_{k}\left[\left[\begin{array}{c}
\varepsilon_{x}^{0} \\
\varepsilon_{y}^{0} \\
\gamma_{x y}^{0}
\end{array}\right]+z\left[\begin{array}{c}
\chi_{x} \\
\chi_{y} \\
x_{x y}
\end{array}\right]\right] .
$$

The resultant external force and the resultant external moment can be expressed as

$$
\begin{aligned}
& {\left[\begin{array}{c}
N_{x} \\
N_{y} \\
N_{x y}
\end{array}\right]=\sum_{k=1}^{N} \int_{Z_{k-1}}^{Z_{k}}\left[\begin{array}{c}
\sigma_{x}^{|k|} \\
\sigma_{y}^{|k|} \\
\sigma_{x y}^{|k|}
\end{array}\right] \mathrm{d} z,} \\
& {\left[\begin{array}{c}
M_{x} \\
M_{y} \\
M_{x y}
\end{array}\right]=\sum_{k=1}^{N} \int_{Z_{k-1}}^{Z_{k}}\left[\begin{array}{c}
\sigma_{x}^{|k|} \\
\sigma_{y}^{|k|} \\
\sigma_{x y}^{|k|}
\end{array}\right] z \mathrm{~d} z .}
\end{aligned}
$$

The parameters in the formula can be determined by experiments.

\section{Experiment and Analysis of the Design and Performance of the Overall Packaging Box of Environmentally Friendly Packaging Materials}

3.1. Problem Description and Model Establishment. Since the actual packaging structure is more complicated, including specific connection forms, such as screws and fins, and the actual packaging model does not form a closed space between each surface, a simplified model of the overall packaging is created based on MSC. Dytran large-scale commercial software is used for transition dynamics, including the introduction of fluid and solid finite element models, material composition relationships, application of acceleration loads, fluid-solid coupling surface, and integral step control and the appearance of a set of basic analysis programs for extracting impact loads. The specific flow chart is shown in Figure 4.

The packaging model defined in this chapter is a simplification of the actual model. Since the actual packaging structure is a thin-walled structure, its thickness is much smaller than the dimensions in the length and width directions. Therefore, in the finite element modeling, shell elements are used to simulate the structure. The packaging material adopts unidirectional board AS4/3502, the single- 


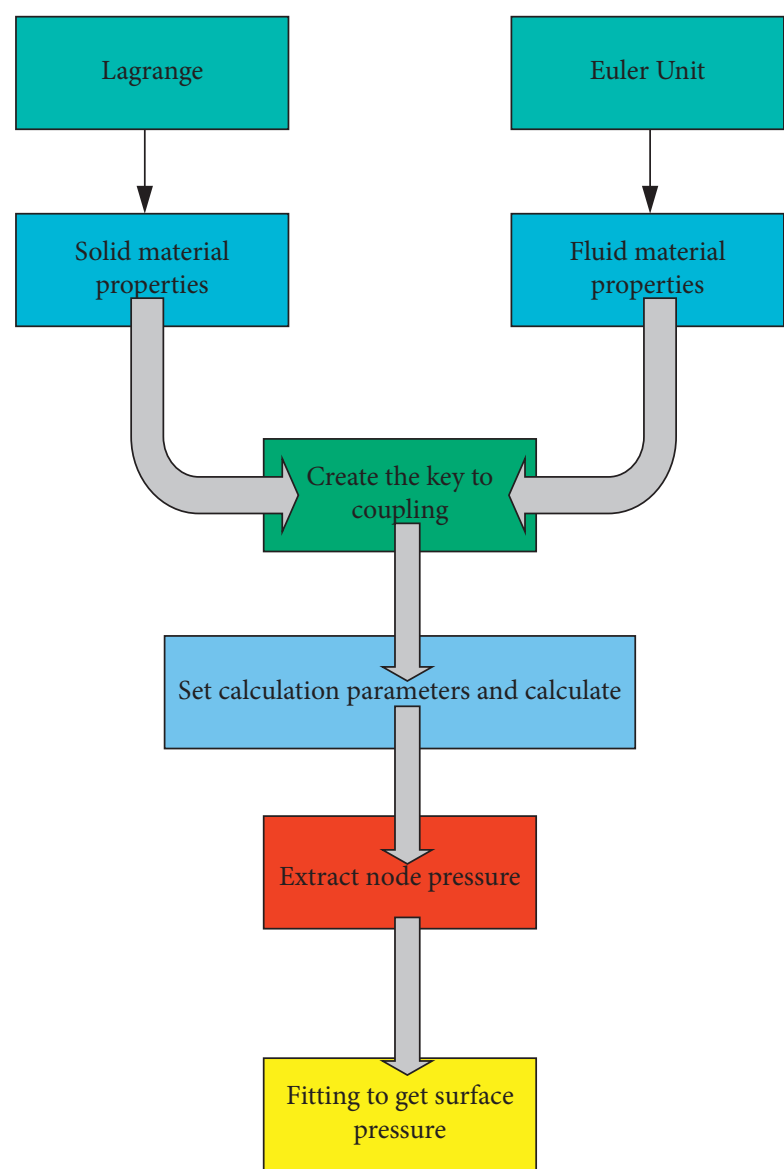

Figure 4: Impact load extraction flow chart.

layer thickness is $0.117 \mathrm{~mm}$, the wall boards are the same, and the symmetrical layout is adopted. The materials of the total lining and the edging are all single-layer materials AS4/ 3502, using symmetrical plates. Material performance parameters are shown in Table 1.

The material parameters of AS4/3602 are shown in Table 2.

The thickness and layering plan of the components of the composite package are shown in Table 3 .

\subsection{Influence of the Coating Process on the Wear Resistance of} Paper-Based Materials. By testing the dynamic friction coefficient of the surface when the cardboard and GCr steel balls are rubbed, the ability of the paper-based packaging material to resist the friction and wear of metal products under different process conditions is analyzed, and the best wear-resistant coating parameters are obtained, thereby developing a coating with wear-resistant function, cloth modified cardboard. The surface of the first-class cowhide noodle box paperboard is made with sulfate carpenter with two layers or one layer. It is suitable for the manufacture of corrugated cardboard for most product packaging. Because of its universality and representativeness, it is used to test the wear resistance of paper-based packaging materials. The chemical composition of the cardboard used in the experiment is shown in Table 4.
TABLE 1: Material parameters of AS4-3502.

\begin{tabular}{lccc}
\hline Parameter name & $\begin{array}{c}\text { Material } \\
\text { parameters }\end{array}$ & Value & Unit \\
\hline Longitudinal modulus of & $E_{1}$ & 127500 & $\mathrm{MPa}$ \\
elasticity & $E_{2}$ & 11300 & $\mathrm{MPa}$ \\
Transverse elastic modulus & $G_{12}$ & 6000 & $\mathrm{MPa}$ \\
In-plane shear modulus & $\mu_{12}$ & 0.3 & - \\
Principal Poisson's ratio & $\rho$ & 1.58 & $\mathrm{~g} /$ \\
Density & $\mathrm{t}$ & 0.117 & $\mathrm{~mm}$ \\
Single-layer thickness & $X_{\mathrm{t}}$ & 1164 & $\mathrm{MPa}$ \\
Longitudinal tensile strength & & &
\end{tabular}

TABle 2: Material parameters of AS4/3602.

\begin{tabular}{lccc}
\hline Parameter name & $\begin{array}{c}\text { Material } \\
\text { parameters }\end{array}$ & Value & Unit \\
\hline Longitudinal compressive strength & $X_{c}$ & 1060 & $\mathrm{MPa}$ \\
Lateral tensile strength & $Y_{t}$ & 42 & $\mathrm{MPa}$ \\
Transverse compressive strength & $Y_{c}$ & 207 & $\mathrm{MPa}$ \\
In-plane shear strength & $S$ & 69 & $\mathrm{MPa}$ \\
\hline
\end{tabular}

TABle 3: Packaging layer and thickness distribution.

\begin{tabular}{lcc}
\hline Area & Laying plan & Thickness $/ \mathrm{mm}$ \\
\hline Packing box siding & {$[ \pm 45 / 90]$} & 5.382 \\
Packing frame ribs & {$\left[45 / 0_{3} /-45 / 90_{2}\right]$} & 3.978 \\
Cover structure & {$[45 / 0 /-45 / 90]_{3}$} & 8.424 \\
Cover ribs & {$\left[ \pm 45 /\left(0_{3} / 45 / 90_{3} /-45\right)_{3}\right]$} & 7.956 \\
\hline
\end{tabular}

The surface friction coefficient of the coated cardboard gradually becomes uniform with time. This is because the coating makes the surface of various quantitative cardboards form a dense coating layer, which changes the original loose and porous paper surface. With the surface being smooth and flat, the coefficient of friction on the surface of all kinds of coated cardboard will be closer. The comparison of the friction coefficient values of different quantitative uncoated and coated box paperboards is shown in Figure 5.

The comparison of the abrasion resistance of the base paper of the box board and the coated box board at different temperatures is shown in Figure 6.

The comparison of the abrasion resistance of cardboard base paper and coated modified paper under different relative humidity conditions is shown in Figure 7.

The uncoated box board paper base of coated box board has much better wear resistance. At RH 50\%, the coefficient of friction of coated cardboard is $49 \%$ lower than that of uncoated cardboard. At RH 90\%, the coefficient of friction of coated cardboard is $60 \%$ lower than that of uncoated cardboard. This means that the higher the relative humidity, the higher the coefficient of friction of the coated paperboard. The abrasion resistance of the uncoated base paper is better than that of the uncoated base paper. This is because the superficial layer of the coated boxboard is filled with 
TABLE 4: Chemical constituents of the first-class kraft faced liner.

\begin{tabular}{lccc}
\hline Chemical name & CAS registry number & EC number & Content (\%) \\
\hline Wood fiber & $65996-61-4$ & $265-995-8$ & 97 \\
Starch & $9005-25-8$ & $232-679-6$ & 1 \\
Styrene-acrylate copolymer & $24981-13-3$ & - & 1 \\
Polyacrylamide & $9003-5-8$ & - & 1 \\
\hline
\end{tabular}

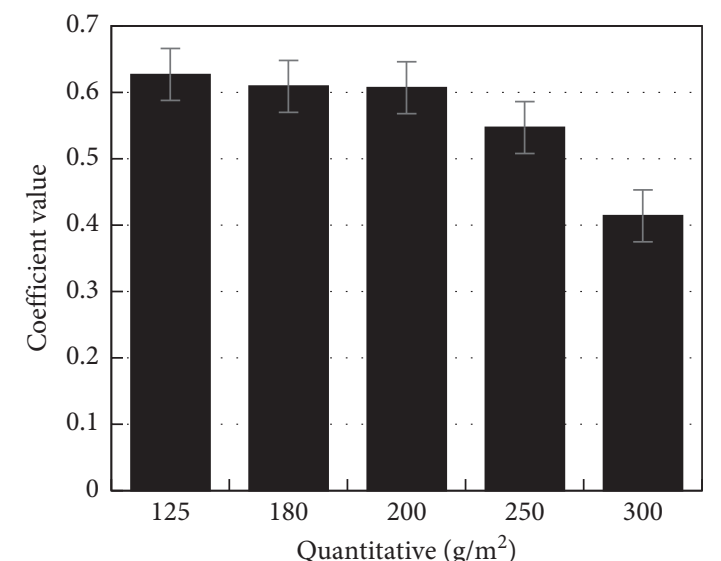

Uncoated cardboard

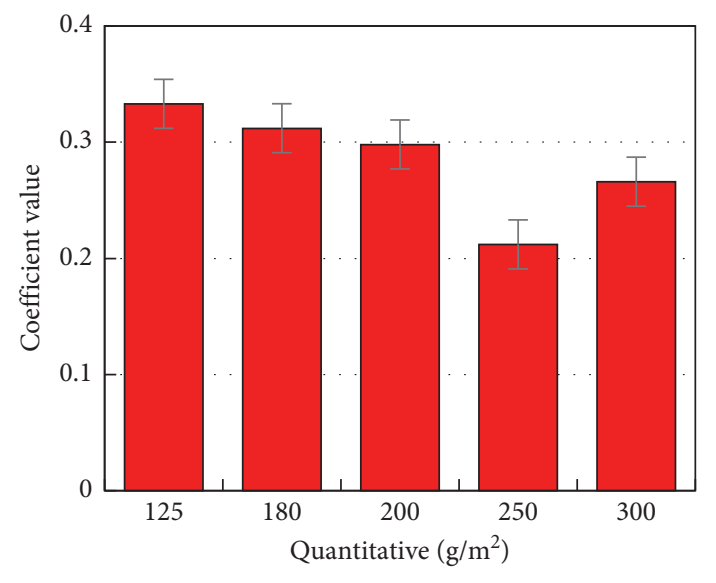

coated cardboard

FiguRE 5: Values of friction coefficient of uncoated and coated cardboard in different quantitative paperboards.

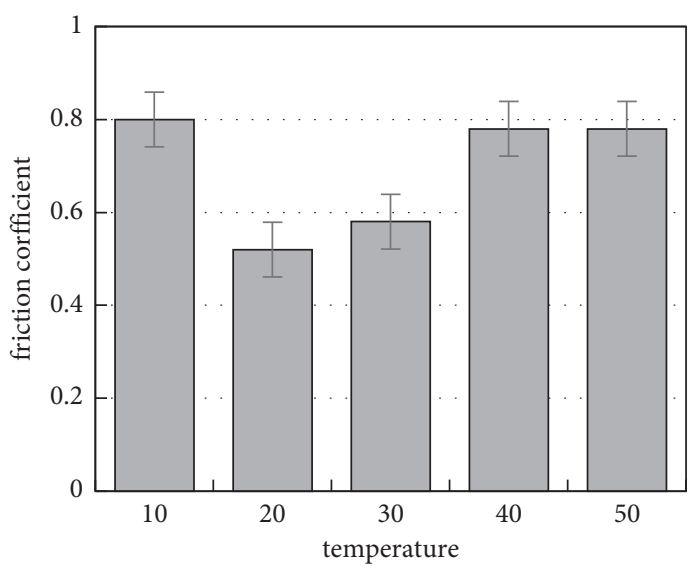

$\square$ Uncoated

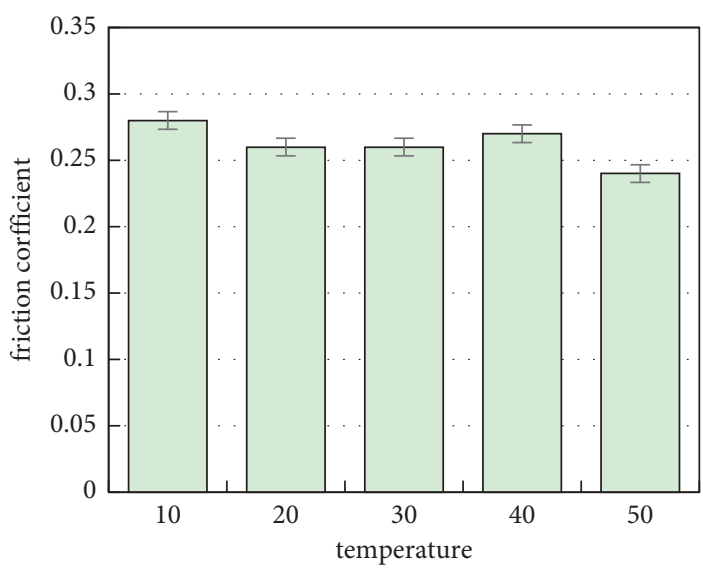

$\square$ coated

FIgURE 6: Abrasion resistance of box board base paper and coated box board at different temperatures.

paint, and a smooth and dense continuous coating film is formed on the surface. The paper fibers are not easy to absorb moisture in the air, so the abrasion resistance is significantly enhanced compared with the uncoated paper.

The buffer performance analysis is shown in Figure 8.

As the compressive load increases, the energy absorption efficiency of the material gradually increases first and then stabilizes. After stability, the relationship between the maximum energy absorption efficiency of each group of samples is NS + UNF $>$ NS + AF.

The preparation of biomass buffer packaging material products is shown in Figure 9.
3.3. Packaging and Sealing Performance. The following will analyze the number of horizontal screws (this article refers to half of the total number of screws in the horizontal direction) and the effect of vertical screws on the maximum relative deformation of the cover under dangerous load conditions. The results are shown in Figure 10.

Obviously, the smaller the number of screws in the two directions, the larger the screw spacing, and the smaller the restriction of the screw on the sealing performance; due to the nonuniformity of the load, the maximum relative deformation is not linear with the number of screws. With the increase in the number of screws, the tendency of the 


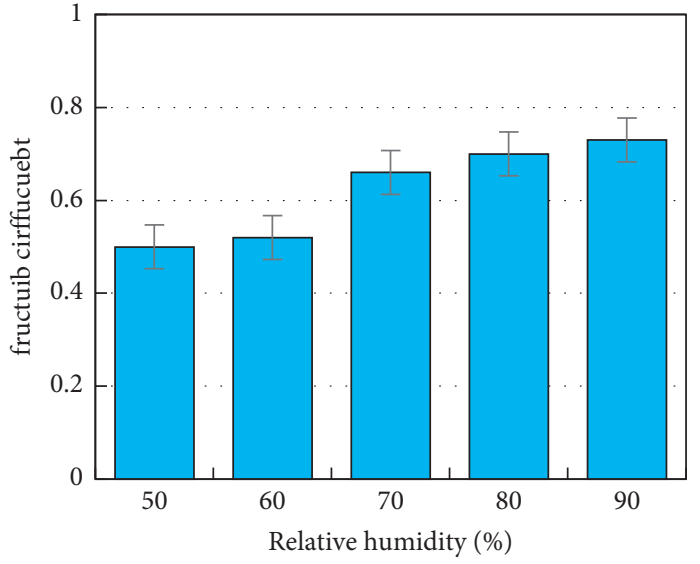

$\square$ Uncoated

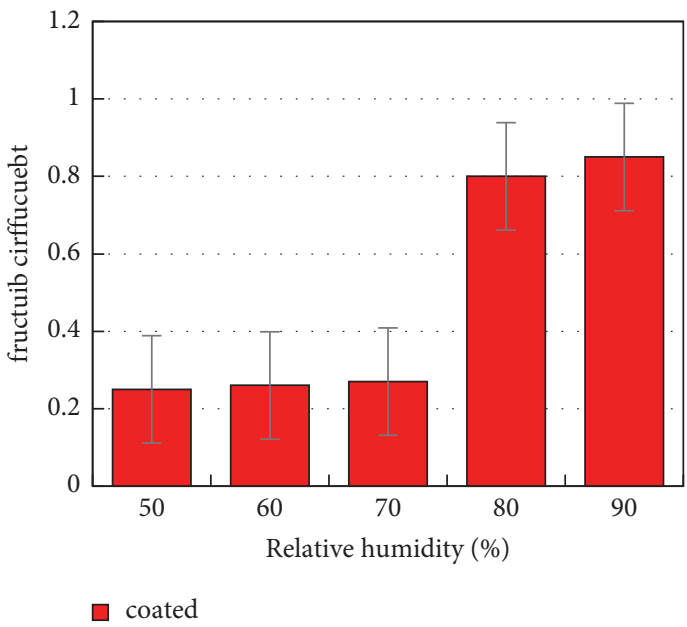

FIGURE 7: Abrasion resistance of cardboard base paper and coated modified paper under different relative humidity conditions.

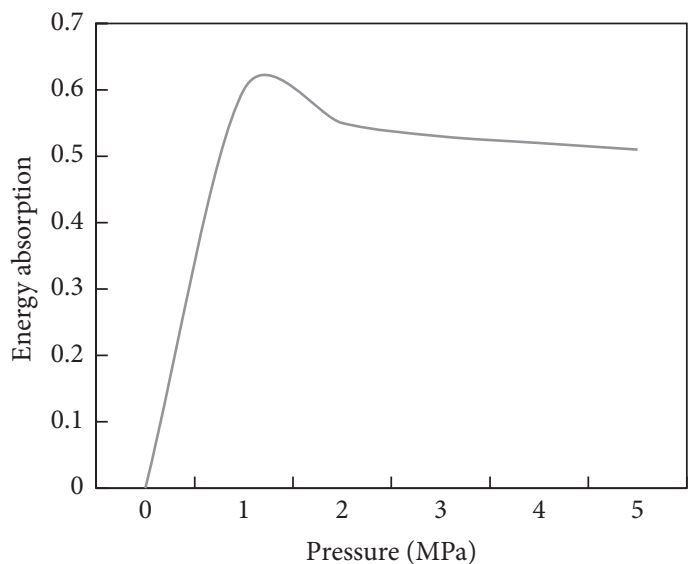

NS+UNF

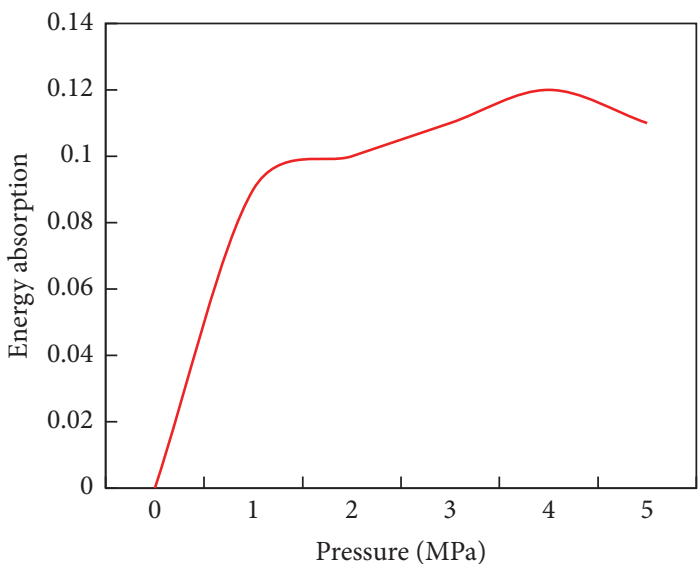

$-\mathrm{NS}+\mathrm{AF}$

FIGURE 8: Buffer performance analysis.

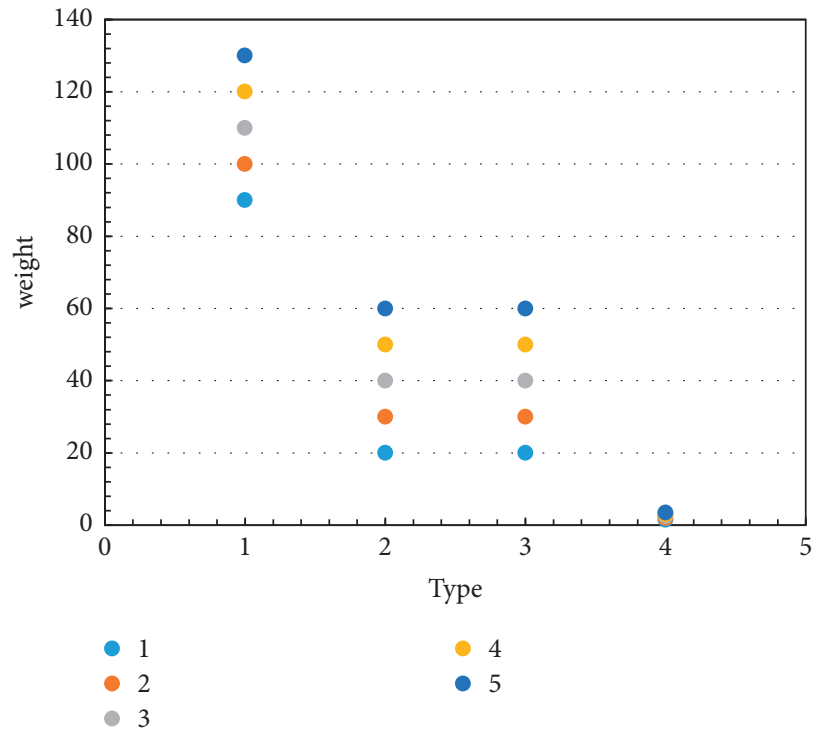

FIGURE 9: Preparation of biomass buffer packaging material products. 


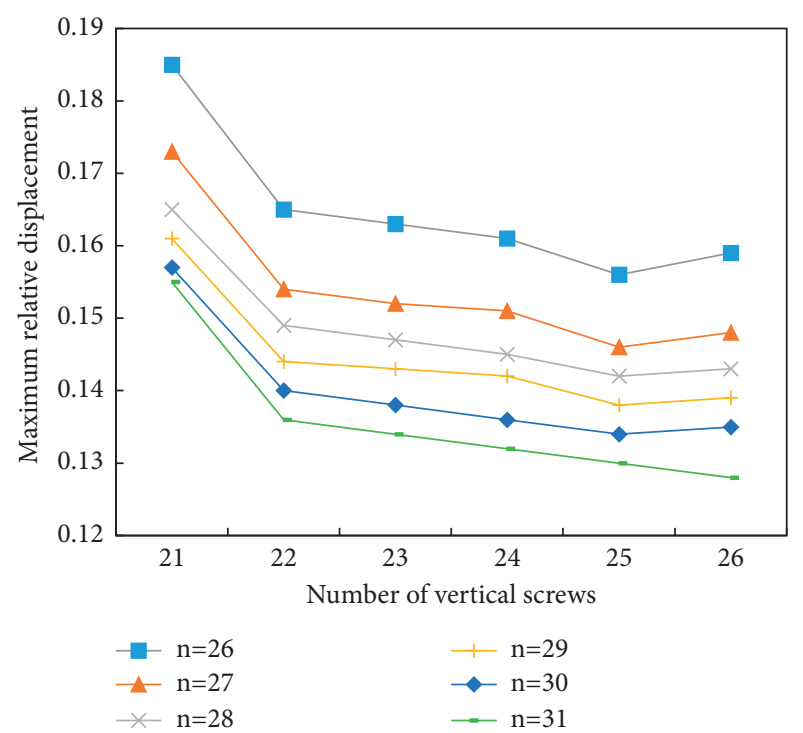

Figure 10: Diagram of the number of screws in the horizontal direction under dangerous load conditions.

maximum relative deformation to become smaller is gradually decreasing.

The value ranges of the optimized design variables are shown in Table 5.

After the first level of optimization, the overall mass of the structure was reduced from the initial $39.42 \mathrm{~kg}$ to $31.18 \mathrm{~kg}$, and the optimization efficiency was $20.90 \%$. The maximum relative deformation of the lid structure increased from $0.143 \mathrm{~mm}$ to $0.198 \mathrm{~mm}$, although the maximum opening displacement increased, but still meeting the sealing deformation requirements.

\section{Discussion on the Design and Performance of the Overall Packaging Box of Environmentally Friendly Packaging Materials}

4.1. Relationship between Materials and Packaging Design. Packaging materials are materials selected for manufacturing packaging, packaging and printing containers, packaging and transportation, and other products that meet packaging requirements. The selection and use of packaging materials must consider various packaging factors. For example, food packaging must be nontoxic and tasteless, and the physical and chemical properties of the packaging must be stable and will not chemically react with the food. For the packaging of goods that must be moistureproof, the packaging material must have good insulation and waterproof properties. If the packaging is fragile, the material must be stable and not easily deformed. In addition, factors such as the transportation of packaging materials, sales arrangements, and market demand for commodities must also be considered.

In the packaging design process, materials and packaging have a very close relationship: from prepackaging design to material selection and then from material selection to design thinking design, designers can have a great influence. In the selection and integration of packaging materials, the designer's design style and personal feelings can be understood from the packaging materials. Therefore, the material is the extension and sublimation of the packaging. Packaging design is a technical issue as well as a very comprehensive issue. This is not only a question of art, but also a question of science and technology. It also covers design, materials science and engineering, social marketing, marketing management, consumer psychology, etc. In addition to making products safe and beautiful, it is also a powerful marketing tool. Packaging design refers to the selection of appropriate materials and the use of certain technologies to design the container structure, shape, and decoration of product packaging.

Packaging materials are materials produced to meet packaging needs and are materials that implement packaging styles. The continuous advancement of science has given birth to the invention and creation of new materials and technologies. There are more and more packaging materials, including traditional packaging materials as well as more innovative high-tech materials. Packaging materials can be classified according to source, use, development, and classification. According to reports, there are two types of packaging materials: one is natural materials, such as wood, bamboo, and rattan. The other is man-made materials, such as plastic, glass, and metal. According to the use, it can be divided into two categories: one is the main packaging materials, such as paper, plastic, metal, wood, ceramics, glass, bamboo, rubber, leather, fabrics, fiber materials, and composite materials. The other is auxiliary packaging materials, such as copper plating, moisture-proof and anticorrosive materials, inks and coatings, adhesives, and other materials that play an auxiliary role in the packaging process and packaging modeling. Different packaging materials have different aesthetic characteristics and also produce different emotions in touch and vision. Designers must first understand the types of materials and then show the beauty of the materials.

Material is an eternal theme in design. Materials are the basis for human survival and construction: after humans seek better physical properties and functions of materials, they meet more needs through construction activities. The external characteristics of the material have a special expressive force in the external application of packaging design and play a direct and effective role. To make packaging products more artistic, it is necessary to fully understand and master the aesthetics of packaging materials. And it is applicable to all aspects of packaging design. A long time ago, people focused on the perfect combination of practicality and aesthetics, realized the important position of materials in design creation, reflected the importance of perceiving the beauty of materials in design, and had a deeper understanding of the beauty of material selection. For packaging design, the use of packaging materials is not only its material basis, but also one of the important contents of aesthetic research and application. The increasing development of science and technology and the abundance of materials have put forward a great demand for the selection and application 
TABLE 5: Design variable value space.

\begin{tabular}{lcc}
\hline Variable name & Initial value & Ranges \\
\hline Number of horizontal screws & 28 & $\{26,27,28,29,30,31\}$ \\
Number of vertical screws & 23 & $\{21,22,23,24,25,26\}$ \\
Stiffener web height & 42 & $40-50$ \\
Width of ribs & 16 & $15-22$ \\
Thickness of cover plate in $0^{\circ}$ direction & 1.170 & $0.1-2.0$ \\
The thickness of the cover plate in the direction of $45^{\circ}$ & 0.936 & $0.1-2.0$ \\
Thickness of cover plate in $90^{\circ}$ direction & 1.170 & $0.1-2.0$ \\
Packaging thickness at $0^{\circ}$ & 0.819 & $0.1-2.0$ \\
Packaging thickness at $45^{\circ}$ & 0.702 & $0.1-2.0$ \\
Packaging thickness at $90^{\circ}$ & 0.469 & $0.1-2.0$ \\
Thickness of ribs & 1.404 & $0.1-2.0$ \\
The thickness of the ribs in the direction of $45^{\circ}$ & 0.585 & $0.1-2.0$ \\
Thickness of ribs in $90^{\circ}$ direction & 1.404 & $0.1-2.0$ \\
\hline
\end{tabular}

of packaging design materials. There are man-made materials, natural materials, composite materials, and individual materials. These have a wide range of applications and development efficiency in packaging technology.

\subsection{Perceiving the Visual Beauty of Materials in Packaging} Design. As a direct and practical marketing method, packaging gives people a visual experience and conveys an easy-to-understand and practical visual language. Eyes are the human body's sensory organs that receive the largest amount of information outside the body. Through the eyes, the most direct, rapid, and accurate perception of packaging materials can be achieved. When stimulated by the information of packaging design materials, vision will form physiological to psychological stimuli and will form different points and consciousness. Through the surface of the packaging design material, the customer visually perceive information, including the color, shape, and design presented by the material, making them produce different emotions.

Among the characteristics of materials, color is the first characteristic that expresses the material, and it is also the first element perceived by all human sensory organs. If you want to whiten and highlight the product, color plays an important role and has a strong appearance and visual charm. The color integrated into packaging materials is the unit of physiological stimulation, psychological stimulation, and aesthetic perception in human visions, and it is also an organic combination of natural characteristics, social characteristics, and artistic beauty. Therefore, the color of packaging materials expresses the beauty of art and provides consumers with the beauty of visual language. The color of the material directly affects the basic packaging style, making it easier for people to communicate with it emotionally. All materials have colors. The color varies with the material, and the material also has a unique visual effect due to the color. The colors of packaging materials are divided into solid colors and additional colors. The inherent color of the material is the natural color of the material itself, and the packaging design has an inherent beauty of value due to the beautiful color of the material, showing a simple and heartfelt feeling. The additional paint is made by processing paint on the surface of natural materials, which can enhance, attenuate, or change the original color and can reasonably improve the relationship between the material and the packaged product according to the consumer or the actual environment. The relationship highlights the accuracy of packaging information delivery.

Color can not only directly attract attention but also can even guide people's psychological emotions. In order to gain the attention of consumers, the packaging of fructose food and beverages generally uses bright colors such as orange and yellow to bring people a sense of beauty, vitality, and happiness. Green and blue mainly give people a feeling of peace, calm, tranquility, and relaxation. These two colors are commonly found in food, energy-saving, and medical packaging materials. In order to meet the needs of consumers, foods often choose high-purity red, yellow, and orange series to reflect the color, fragrance, and taste. In packaging design, in addition to examining the color coordination of materials, it is also necessary to examine whether the feel of the color itself is consistent with the characteristics of the product. The warm and cold colors give people a strong psychological impact, while the pure colors give people the feeling of being generous and noble and spotless. The order of beauty is used in the packaging design to combine and match the colors of the materials, so that the weight, contrast, and direction of the colors convey visual information, so as to use the enjoyment of beauty in people's psychology. Combining the new elements of modern colors, we analyze the color aesthetic law of packaging design, meet the possible requirements of packaging design, and design better and more suitable packaging design products.

4.3. Economy of Material Beauty in Packaging Design. The beauty and economy of materials in packaging design refers to the comprehensive evaluation of the amount of packaging materials used in the product and the degree of conservation of energy and resources consumed in the production and processing of packaging materials. Nowadays, affected by the increasing proportion of the added value of packaging design in the total value of the product, cumbersome styles, luxurious materials, and bulky packaging have followed one after another, causing packaging design materials to be 
distorted. The economy of material beauty in packaging design includes two aspects: convenience and simplicity of material use.

"Appropriate" is the most beautiful and accurate means of reasoning. A successful packaging product does not mean that the rarer the material and the higher the price, the better. The most appropriate should be based on the value of the product, the needs of consumers, and the environment in which they are used. "Appropriate packaging refers to a reasonable and appropriate packaging product. It is to fully explore the functional role of packaging. The protective function of packaging must be fully considered. The quantity of materials, cost prices, and complete labels must be fully considered." Appropriate packaging adjustment function and cost are very important. According to the product packaging, appropriate specific standards are established for the manufacturer, using appropriate packaging methods, packaging materials, material use, and appropriate packaging development. Ecobeauty needs a simple and convenient product packaging structure to improve the quality of product manufacturing while having mass production.

In order to eliminate the harmful effects of excessive packaging of products, the General Administration of Quality Supervision, Inspection and Quarantine and other relevant departments jointly formulated the provisions of GB 23350-2009 "Requirements for Restricting Excessive Packaging of Goods, Food and Cosmetics". Appropriate guidance and restrictions on the correct use of packaging materials have been made at all levels. Therefore, when designing packaging materials, the choice of materials must be based on the unique characteristics and economic benefits of the product.

\section{Conclusions}

The experimental results show that the overall packaging box design and performance discussion of environmentally friendly packaging materials proposed in this paper have improved airtightness, environmental protection, and capacity compared with the design of traditional packaging materials. The design method selected in this article has a good retention rate in terms of statistical indicators. The article introduces the relevant content of zero-pollution packaging, calculates the positive axis stiffness of the singlelayer board, and studies the stiffness performance of the single-layer composite material on the positive axis. Through the material constitutive relationship, acceleration load application, fluid-solid coupling surface, and integration step control, a set of basic analysis processes for extracting impact load is derived. The actual model is simplified to a packaging model, and good experimental results are obtained. Experimental data show that after the first level of optimization, the overall mass of the structure is reduced from the initial $39.42 \mathrm{~kg}$ to $31.18 \mathrm{~kg}$, and the optimization efficiency is $20.90 \%$; the maximum relative deformation of the flap structure has increased from $0.143 \mathrm{~mm}$ to $0.198 \mathrm{~mm}$, although having the maximum tension. The opening displacement has increased, but it still meets the sealing deformation requirements. The shortcomings of this article are that the amount of data collected in the sample is relatively limited and the requirements of different aspects of the designed packaging may not be comprehensive. In future research, the experimental samples can be expanded to obtain the credibility of the research results. In addition, the article's introduction to algorithm comparison is not comprehensive enough, and there is no increase in citations and explanations of other algorithms for comparison. In future experiments, relevant content can be added to make the article more reasonable.

\section{Data Availability}

No data were used to support this study.

\section{Conflicts of Interest}

The author declares no conflicts of interest in this study.

\section{Acknowledgments}

This work was supported by project funding of the National Social Science Foundation Art Project "Yunnan Design History" (19CG184) Phased Achievement.

\section{References}

[1] A. C. Neves, M. M. Moyne, C. Eyre, and B. P. Casey, "Acceptability and societal impact of the introduction of bioplastics as novel environmentally friendly packaging materials in Ireland," Cleanroom Technology, vol. 2, no. 1, pp. 127-143, 2020.

[2] Y. Wang and Y. Wang, "Research on the application of environmentally friendly packaging materials in the sustainable development of logistics," IOP Conference Series: Earth and Environmental Science, vol. 781, no. 3, pp. 25-32, 2021.

[3] G. Vahid and S. G. Iman, "Development of photo-modified starch/kefiran/ $/ \mathrm{TiO}_{2}$ bio-nanocomposite as an environmentally-friendly food packaging material," International Journal of Biological Macromolecules, vol. 116, no. 2, pp. 1082-1088, 2018.

[4] F. Nurul, J. Krishnan, B. Debes et al., "Green composites made of bamboo fabric and poly (lactic) acid for packaging applications-a review," Materials, vol. 9, no. 6, pp. 55-65, 2016.

[5] Q. Wang, J. Yang, P. Liu, and L. Li, "Facile one-step approach to manufacture environmentally friendly poly(vinyl alcohol) bead foam products," Industrial \& Engineering Chemistry Research, vol. 60, no. 7, pp. 2962-2970, 2021.

[6] D. Dissanayake, D. Weerasinghe, T. Perera et al., "A sustainable transparent packaging material from the arecanut leaf sheath," Waste and Biomass Valorization, vol. 7, no. 3, pp. 1-18, 2021.

[7] Puscaselu, Gheorghita, Roxana et al., "The application of the peleg model in order to obtain completely soluble materials for food product packaging," Journal of Applied Packaging Research, vol. 10, no. 1, pp. 6-7, 2018.

[8] S. H. Jo, T. H. Ryu, H. Kwon et al., "Ecological characteristics and environmentally friendly control strategies of pochazia shantungensis (Hemiptera: ricaniidae) in korea," Journal of the Faculty of Agriculture, Kyushu University, vol. 61, no. 2, pp. 299-311, 2016. 
[9] A. K. . Bolhassan, "Sweden takes lead on eco-friendly food packaging," Paper Asia, vol. 35, no. 1, pp. 2-5, 2019.

[10] C. Aversa, M. Puopolo, and M. Barletta, "Tailor-made bioplastics for environmentally friendly food packaging: a methodological approach to a challenging problem," Encyclopedia of Renewable and Sustainable Materials, vol. 4, no. 8, pp. 605-616, 2020.

[11] U. Hasanah, E. P. S. Dewi, U. Santoso, and S. Supriyadi, "Physical and chemical characteristic of young coconut leaves (cocos nucifera 1.) as traditional packaging," Indonesian Food and Nutrition Progress, vol. 17, no. 2, pp. 33-44, 2021.

[12] A. K. Gain, L. Zhang, and M. Z. Quadir, "Thermal aging effects on microstructures and mechanical properties of an environmentally friendly eutectic tin-copper solder alloy," $\mathrm{Ma}$ terials \& Design, vol. 110, no. 15, pp. 275-283, 2016.

[13] M. Combrzyński, A. P. Matwijczuk, A. Wójtowicz et al., "Potato starch utilization in ecological loose-fill packaging materials-sustainability and characterization," Materials, vol. 13, no. 6, pp. 13-90, 2020.

[14] A. Masek, M. Latos, M. Piotrowska, and M. Zaborski, "The potential of quercetin as an effective natural antioxidant and indicator for packaging materials," Food Packaging and Shelf Life, vol. 16, no. 9, pp. 51-58, 2018.

[15] M. Joyce, L. Pal, and T. Tran, "Production of polyhydroxyalkanoates (PHA)-based renewable packaging materials using photonic energy: a bench and pilot-scale study," Octobr 2018, vol. 17, no. 10, pp. 557-565, 2018.

[16] B. Geueke, K. Groh, and J. Muncke, "Food packaging in the circular economy: overview of chemical safety aspects for commonly used materials," Journal of Cleaner Production, vol. 193, no. 9, pp. 491-505, 2018.

[17] T. Giro, K. Beloglazova, G. Rysmukhambetova et al., "Xanthan-based biodegradable packaging for fish and meat products," Foods and Raw Materials, vol. 8, no. 1, pp. 67-75, 2020.

[18] M. Mironescu, A. S. Lazea, M. E. P. Barbinta et al., "Green design of novel starch-based packaging materials sustaining human and environmental health," Polymers, vol. 13 , no. 8 , pp. 1190-1198, 2021.

[19] Y. Zhang, L. Zhan, B. Xie et al., "Decomposition of packaging materials and recycling GaAs from waste ICs by hydrothermal treatment," ACS Sustainable Chemistry \& Engineering, vol. 7, no. 16, pp. 98-101, 2019.

[20] R. M. Raybaudi, J. M. Mosqueda, R. F. Soliva, and O. B. Martín, "Combinational edible antimicrobial films and coatings," Antimicrobial Food Packaging, vol. 8, no. 11, pp. 633-646, 2016.

[21] A. Lisitsyn, A. Semenova, V. Nasonova et al., "Approaches in animal proteins and natural polysaccharides application for food packaging: edible film production and quality estimation,” Polymers, vol. 13, no. 10, pp. 1592-1598, 2021.

[22] Y. Xu, X. Liu, Q. Jiang et al., "Development and properties of bacterial cellulose, curcumin, and chitosan composite biodegradable films for active packaging materials," Carbohydrate Polymers, vol. 260, no. 2, pp. 117-778, 2021.

[23] B. Bayram, G. Ozkan, T. Kostka, E. Capanoglu, and T. Esatbeyoglu, "Valorization and application of fruit and vegetable wastes and by-products for food packaging materials," Molecules, vol. 26, no. 13, pp. 4031-4032, 2021.

[24] M. B. Latos and A. Masek, "Biodegradable polyester materials containing gallates," Polymers, vol. 12, no. 3, pp. 77-78, 2020.

[25] M. Lamb, V. Rouillard, and J. Milverton, "An evaluation of the mechanical performance of extruded wheat starch loose fill,"
Packaging Technology and Science, vol. 32, no. 2, pp. 99-101, 2019.

[26] S. B. Tsai, M. F. Chien, Y. Xue et al., "Using the fuzzy dematel to determine environmental performance: a case of printed circuit board industry in taiwan," PLoS One, vol. 10, no. 6, Article ID e0129153, 2015.

[27] S. B. Tsai, Y. C. Lee, and J. J. Guo, "Using modified grey forecasting models to forecast the growth trends of green materials," Proceedings of the Institution of Mechanical Engineers - Part B: Journal of Engineering Manufacture, vol. 228, no. 6, pp. 931-940, 2014.

[28] J. Zhao, J. Huang, Y. Xiang et al., "Effect of a protective coating on the surface integrity of a microchannel produced by microultrasonic machining," Journal of Manufacturing Processes, vol. 61, pp. 280-295, 2021. 